\title{
Does a home-based interview with a chronically ill patient help medical students become more patient-centred? A randomised controlled trial
}

\author{
Michael Harris ${ }^{1,2,3^{*}}$ (D) Anna-Lea Camenzind ${ }^{1}$, Rita Fankhauser ${ }^{1}$, Sven Streit ${ }^{1}$ and Roman Hari $^{1}$
}

\begin{abstract}
Background: While patient-centred care improves patient outcomes, studies have shown that medical students become less patient-centred with time, so it is crucial to devise interventions that prevent this. We sought to determine whether first-year medical students who had a structured home-based interview with a chronically ill patient became more patient-centred than those who had a sham intervention.

Methods: This randomised controlled trial assigned first-year students from the University of Bern, Switzerland, to either an interview with a chronically ill patient at the patient's home or to a sham comparator. We used the PPOSD12 questionnaire to measure students' levels of patient-centredness at baseline, and changes in these levels during their longitudinal primary care clerkship.

Results: A total of 317 students participated. Patient-centred attitudes increased during the study. A home-based interview with a chronically ill patient had no additional effect. Being female and having been exposed to patients before medical school were associated with being more patient-centred at baseline. Students were less patientcentred than their General Practitioner teachers.

Conclusions: A structured, home-based interview with a chronically ill patient did not change students' patientcentred attitudes, so cannot be recommended as a way to influence those attitudes. However, patient-centred attitudes increased during the students' first year of study, possibly because of their longitudinal primary care clerkship.
\end{abstract}

Trial registration: Clinicaltrials.gov reference: NCT03722810, registered 29th October 2018.

Keywords: Medical professionalism, Patient-centred care, Primary health care, Undergraduate medical education

\footnotetext{
* Correspondence: michael.harris@biham.unibe.ch

${ }^{1}$ Institute of Primary Health Care (BIHAM), University of Bern, Bern,

Switzerland

${ }^{2}$ College of Medicine \& Health, University of Exeter, Exeter, UK

Full list of author information is available at the end of the article
}

(c) The Author(s). 2020 Open Access This article is licensed under a Creative Commons Attribution 4.0 International License, which permits use, sharing, adaptation, distribution and reproduction in any medium or format, as long as you give appropriate credit to the original author(s) and the source, provide a link to the Creative Commons licence, and indicate if changes were made. The images or other third party material in this article are included in the article's Creative Commons licence, unless indicated otherwise in a credit line to the material. If material is not included in the article's Creative Commons licence and your intended use is not permitted by statutory regulation or exceeds the permitted use, you will need to obtain permission directly from the copyright holder. To view a copy of this licence, visit http://creativecommons.org/licenses/by/4.0/. The Creative Commons Public Domain Dedication waiver (http://creativecommons.org/publicdomain/zero/1.0/) applies to the data made available in this article, unless otherwise stated in a credit line to the data. 


\section{Background}

In patient-centred practice, clinicians and patients share control of the consultation and of decisions about management of health problems, and physicians see their patients in a social context [1]. Patient-centred clinicians take the patient's preferences and desires into account and integrate them into a care plan that is negotiated between them; they seek to understand patients as well as their diseases, to 'see the illness through the patient's eyes' [2]. Patient-centred care is associated with favourable biomedical, psychological and social outcomes [3], can increase patient satisfaction [1], and can encourage patients to share useful information [4]. The degree to which health care is patient-centred can be viewed as a measure of its quality [5].

While medical students feel that a patient-centred approach is an important part of medical professionalism [6], longitudinal studies in the USA [7], Greece [8] and South Africa [9] found that students grew less patientcentred during their undergraduate course. A Japanese study found that resident physicians at a university hospital also became less patient-centred over the course of the year [10]. However, increasing patient-centred practice through interventions is challenging. One study that assessed the effect of interpersonal skills lectures and teaching on practitioner-patient interaction found that this did not significantly increase patient-centred practice in first-year undergraduates [11]. Early patient contact may, however, be effective: a study investigating the perspectives of tutors and students on the increasing students' awareness of professionalism in the early years at a Scottish university found that early patient contact experiences were particularly important [12]. The study also found that learning activities that promoted critical reflection had a positive effect, and that role models contributed powerfully to students' learning and identity formation.

Many medical schools have redesigned their curricula to help their students deliver person-centred healthcare [13]. Some have used home visits for this: home visits have been found to teach students how individualised care helps to meet chronically ill patients' needs, and students have reported that the experience heightens their empathy and sensitivity towards these patients [14]. Student home visits result in more positive attitudes to their patients, in that they increase behaviours and attitudes that promote patients' and families' best interests [15], and they have been found to be a time-effective way of fostering students' professional growth [16]. The timing of students' home visits during their undergraduate career is also important, with evidence that they have a stronger positive effect on students' attitudes when performed earlier [17]. Home visits to chronically ill patients can have a profound effect: there is evidence that they continue to positively influence students over subsequent years, with some reporting vivid memories of patients they had seen, and that when caring for patients 2 years later they were still applying the lessons they had learned [14].

To encourage students to take a patient-centred approach, we therefore designed a teaching module that took these factors into account. First-year medical students were assigned to visit a chronically ill patient in their own home and conduct a structured in-depth interview that used open-ended questions to elicit the patient's narrative, and then participate in a structured debriefing with their General Practitioner (GP) teacher. To assess the effectiveness of this module, we conducted a randomised controlled trial to investigate whether these students subsequently had more patient-centred attitudes than those who had a sham intervention.

\section{Methods \\ Design}

This randomised controlled trial was conducted at the University of Bern, Switzerland and affiliated GP teaching practices between September 2018 (recruitment) and June 2019 (end of follow-up). All first-year medical students were randomly assigned to either the intervention arm or a sham comparator, which took place during one of the last days of their longitudinal clerkship in primary care.

\section{Interventions}

The active intervention was a structured, in-depth interview with a chronically ill patient that had been chosen by the student's allocated GP teacher. Each GP teacher was asked to select a patient who had one of the four chronic diseases with the highest disability-adjusted life years (DALY) scores in Switzerland: ischaemic heart disease, low back pain, major depressive disorder and chronic obstructive pulmonary disease [18]. GP teachers and students were told that these interviews needed to be unaccompanied and conducted at patients' own homes. A structured debriefing discussion with the GP teacher followed each interview.

The comparator was a sham intervention in which GP teachers were asked to give students time to read a document that taught students about consultation skills and asked questions that the students needed to discuss with their GP teachers. This self-study document was designed to provide educational value and complement the University's consultation skills teaching. We selected this as a sham intervention because there was existing evidence that teaching students interpersonal skills and training them in practitioner-patient interaction did not make them more patient-centred [11]. 
In their first months of medical school, students received seven half-days of training in primary care clerkships. To this, we added the half-day assigned for the study interventions. Students had no other patientrelated experience or training during the observation period, which primarily consisted of teaching in the basic medical sciences.

\section{Outcome measures}

We assessed patient-centred attitudes with the PatientPractitioner Orientation Scale (PPOS) [19]. The original English-language version was designed to differentiate between patient-centred and doctor-centred attitudes [8], and is used to assess attitude changes in medical student cohorts as they progress through the clinical curriculum. We used a German-language version, PPOSD12, which has been validated as an instrument for assessing patient-centred attitudes among medical students in German-speaking countries [20] (English translation given in Additional file 1).

The primary outcome measure was how the change in students' PPOS-D12 scores over the time of their sixmonth primary care attachment compared between the active and sham intervention groups. Secondary outcomes were overall change in students' PPOS-D12 scores during course of the study, and the effect on their baseline PPOS-D12 scores of: students' gender; whether they had previously studied another subject as an undergraduate; pre-medical school contact with patients; and prior experience of chronic illness in the participants themselves or their close relatives and friends.
Experiences of their mentors' behaviours, both positive and negative, shape medical students' perceptions of the profession's values [21-23]. We therefore hypothesised that students' patient-centred attitudes might change to become more similar with those of their GP teachers, and conducted a nested study to compare changes in the PPOS-D12 scores of students with those of their GP teachers.

\section{Data collection}

At the start of their first academic year, before they began their six-month primary care attachment, students completed an online survey that asked for demographic information and then administered the PPOS-D12.

After the interventions, students completed a second online questionnaire that asked which intervention they had been allocated to and which they had actually received, and again administered the PPOS-D12. Students who did not complete the survey were sent multiple reminders. Their GP teachers also completed an online PPOS-D12 survey after their attachment to the student had ended. Surveys were not anonymous, so that we could link student and teacher data.

The study is represented diagrammatically in Fig. 1.

\section{Development of the interventions}

We designed the active intervention after reviewing and discussing the existing literature. Students were asked to visit a chronically ill patient in their own home and conduct an in-depth interview. They were given an interview guide, which helped students to elicit their patients' views on their illnesses, and to ask about the physical,

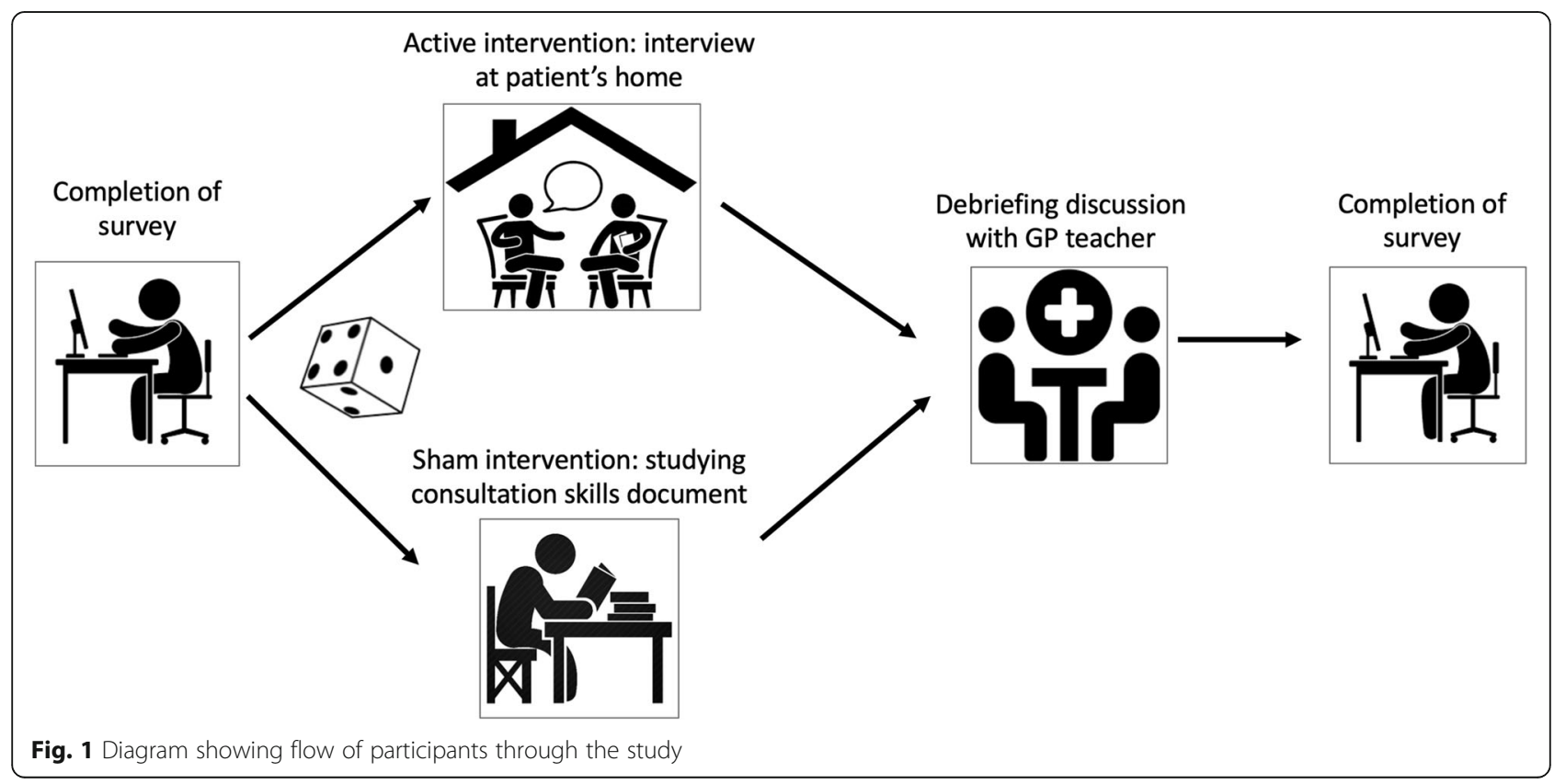


psychological and social effects that were a consequence of them. It gave open-ended questions that invited patients to talk about their lives and let students get to know their patients and their role in their families, as these have been found to be key in encouraging patientcenteredness [24]. Questions that encouraged a storytelling approach were used; this has been found to encourage patient-centred practice, by allowing clinicians to learn more about the patient as an individual, and to gain a better understanding of their personal meanings, experiences, and attitudes [25]. The sections of the interview guide were designed to map across to Mead and Bower's conceptual framework of patient-centredness [26]. As the students were in their first year, so were mainly young and had little or no experience in interviewing patients, we designed the guide to make it easy for students to use it as a script. It was structured to ensure that they would cover the pertinent topics and use open-ended questions. The interviews were designed to last $60-90 \mathrm{~min}$. The patient visits were followed by a $30-$ min student/GP teacher debriefing discussion, a process which helps learners make sense of their experience and reflect on their practice [27-29]. A proforma for the debriefing with the GP teacher prompted the students to summarise their consultation, reflect on their view of the patient as a person, and discuss what they learnt from the process, promoting reflective observation and abstract conceptualization, two core components of Kolb's learning cycle [30].

Six medical students piloted the intervention with patients selected by their GP teachers and then participated in a focus group, led by RF, to discuss how well the interview guide worked and any organisational problems that they had encountered. The focus group was audio-taped and transcribed verbatim; thematic analysis was used to provide a descriptive thematic summary. Where the focus group identified weaknesses in the organisation of the patient interviews or in the patient interview guide, we used our findings to improve the guide and the information sheets for patients, students and GP teachers. Three medical students then piloted the updated interview guide, with one of the researchers (A-LC) role-playing the patient. The students gave feedback and recommendations on how the guide could be further improved. The pilots focussed on the practical aspects of implementing the intervention, including the ability of the intervention to promote patientcenteredness by letting students elicit their patients' views on their illnesses and the effects on them, and getting patients to talk about their lives and the role they play in their families [23]. Taking these findings into account, RF, A-LC and MH further revised and finalised the patient interview guide (available from http://www. tinyurl.com/patient-centredness). The interview guide and instructions on how to organise the interview, including advice on students' personal safety, were sent to students and their GP teachers before the students' final visits to their teaching practices.

For the sham intervention, $\mathrm{MH}$ wrote a 1850 -word (9 page) self-study guide called 'Communication skills for medical students' (available from http://www.tinyurl. com/patient-centredness). We sent it, with instructions on how to use it, to students and their GP teachers before the students' final visits to their teaching practices.

\section{Sample size}

Considering data from the literature [24], we powered the study to detect a mean between-group difference in PPOS-D12 scores of 0.16, with an SD of 0.42 and an effect size of 0.38 . To detect this difference, with a power of $80 \%$ and a significance level of $5 \%$, we calculated that 218 students would be needed, with a minimum of 109 in each group. To allow for a $20 \%$ drop-out rate, we therefore aimed to enrol a minimum of 275 students.

\section{Randomisation}

We sent a list of all study participants to a central University agency (Clinical Trials Unit, University of Bern) where researchers used simple random sequences generated in the IBM SPSS (Version 22) statistical package to allocate participants, without stratification, to either the active or the sham intervention.

\section{Blinding}

The researcher who performed the randomisation was blinded to the purpose of the interventions. To minimise performance and other reporting biases, we told students that they were randomised to one of two intervention groups, but we did not reveal that one was a sham comparator. We took the same approach with information sent to their GP teachers.

\section{Statistical analysis}

We converted the PPOS-D12 survey Likert scale answers to a numerical score, ranging from 1 ('I completely agree') to 6 ('I completely disagree'). For all the survey statements, 'I completely agree' was the most doctorcentred answer and 'I completely disagree' was the most patient-centred. For each respondent, the PPOS-D12 score was the mean of the scores for the twelve statements, so the lowest possible mean score (most doctorcentred) was 1 , the highest possible mean score (most patient-centred) was 6 .

For the primary outcome measure, to adjust for a difference in baseline PPOS-D12 scores between the two intervention groups, and after exploration of the data suggested that the effect of the baseline scores was linear, we compared the mean difference in the study start 
and end PPOS-D12 scores for the active and sham intervention groups using analysis of covariance (ANCOVA).

To measure secondary outcomes, we used linear regression to determine the effect of students' baseline characteristics on PPOS-D12 scores at start of study, and a paired $t$ test to determine the mean change over time of all student' PPOS-D12 scores.

For the nested study, we used a paired $t$ test to assess the difference between GP teachers' PPOS-D12 scores and their students' scores. We used the Pearson correlation coefficient to measure the association between GP teachers' PPOS-D12 scores and changes in their students' scores.

\section{Results}

Of the 326 students eligible for the study, 317 agreed to participate. On randomisation, 157 were allocated to the active intervention (patient interview), and 160 to the sham intervention (communication skills document), of which 150 (95.5\%) and 156 (97.5\%) students respectively completed both the study start and end PPOS-D12 surveys. All students received their allocated intervention. Eleven students were lost to follow-up (see CONSORT diagram, Fig. 2).

\section{Baseline characteristics}

Of the 306 students who completed both surveys, 195 $(63.7 \%)$ were women (Table 1$)$. In the first survey, 102 (33.3\%) indicated that they had experienced a serious, chronic illness in themselves, a friend or a close relative; 36 (11.8\%) had studied another subject as an undergraduate before they started studying medicine; 108 (35.3\%) had had contact with patients before they started at medical school. The mean PPOS-D12 score of all students combined was 4.19 at the start of the study. Despite the random allocation, we noted a significant

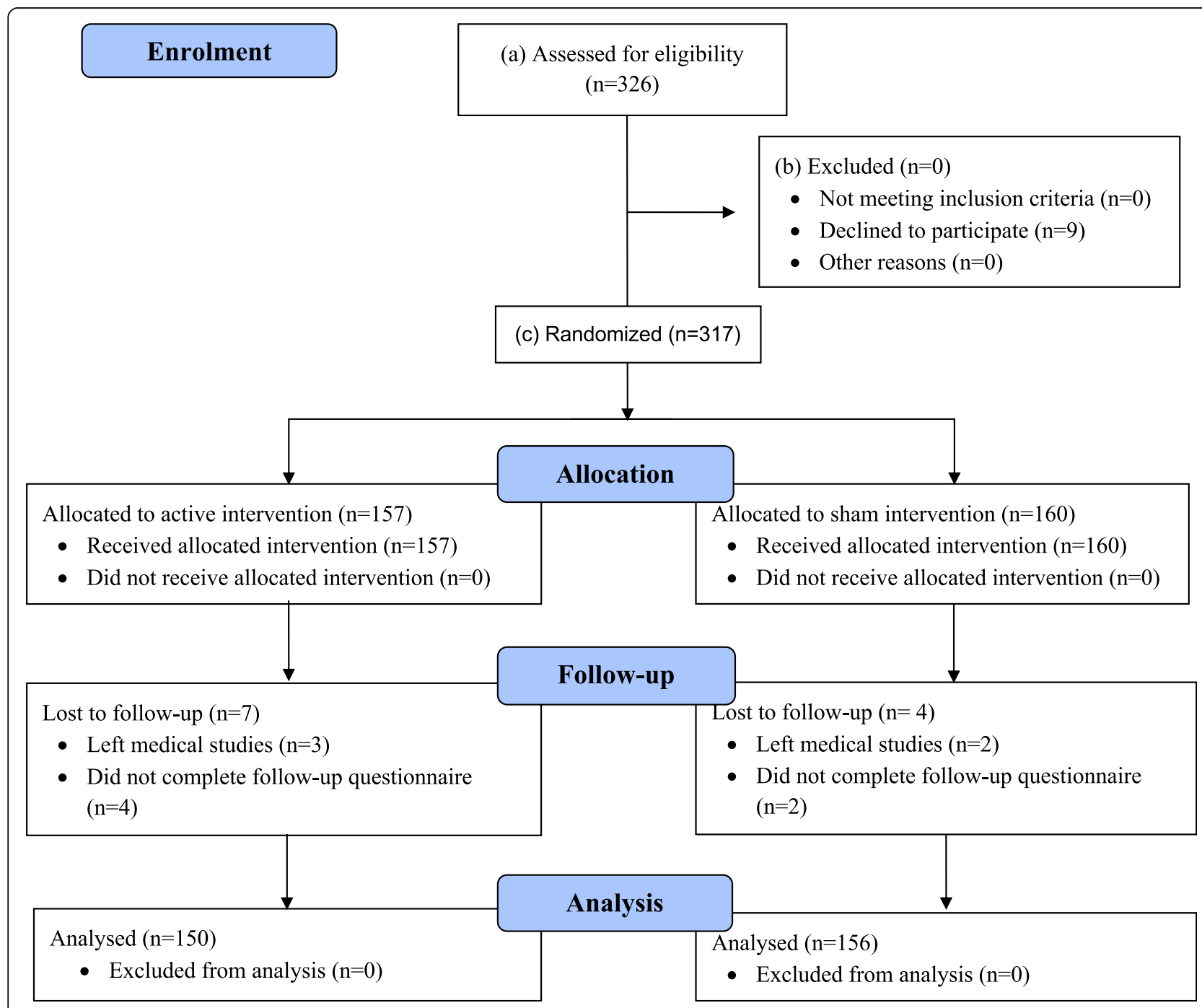

Fig. 2 CONSORT 2010 Flow Diagram 
Table 1 Students' characteristics and mean PPOS-D12 scores at start of study

\begin{tabular}{llll}
\hline Characteristic & $\begin{array}{l}\text { All participants completing } \\
\text { both surveys }(n=306)\end{array}$ & $\begin{array}{l}\text { Allocated to active } \\
\text { intervention } \\
(n=150)\end{array}$ & $\begin{array}{l}\text { Allocated to sham } \\
\text { intervention } \\
(n=156)\end{array}$ \\
\hline Female, number (\%) & $195(63.7)$ & $92(61.3)$ & $103(66.0)$ \\
Personal experience of a serious chronic illness, number (\%) & $102(33.3)$ & $55(36.7)$ & $47(30.1)$ \\
Had previously studied another subject as an undergraduate, number (\%) & $36(11.8)$ & $19(12.7)$ & $17(10.9)$ \\
Contact with patients before starting at medical school, number (\%) & $108(35.3)$ & $59(39.3)$ & $41(31.4)$ \\
Baseline PPOS-D12 score ${ }^{*}$, mean (SD) & $4.19(0.47)$ & $4.25(0.44)$ & $4.14(0.50)$ \\
\hline
\end{tabular}

${ }^{*}$ The lowest possible PPOS-D12 score (most doctor-centred) was 1, the highest possible score (most patient-centred) was 6

difference between PPOS-D12 scores in the two groups at the start of the study (active intervention: 4.25, sham intervention: 4.14, $P=0.031$ ).

\section{Active intervention group: type of chronic disease and site of interview}

Of the students allocated to the active intervention, $138(92.0 \%)$ visited their patients at home or in residential accommodation; 11 (7.3\%) saw their patients in their GPs' practice; 76 (50.7\%) interviewed patients with one of the four specified chronic diseases, and all but one of the other students saw patients with another significant chronic condition (Table 2). All students saw their GP teachers for a debriefing discussion.

Table 2 Site of interview and type of chronic disease

Number (\%)

\begin{tabular}{ll}
\hline Site of interview & \\
Patient's home & $125(83.3)$ \\
Other residential accommodation & $13(8.7)$ \\
GP practice & $11(7.3)$ \\
Another site & $1(0.7)$ \\
Type of chronic disease & \\
Ischaemic heart disease & $27(18.0)$ \\
Chronic low back pain & $21(14.0)$ \\
Major depressive disorder & $6(4.0)$ \\
Chronic obstructive pulmonary disease & $22(14.7)$ \\
Chronic neurological disease & $18(12.0)$ \\
Chronic musculoskeletal disease & $14(9.3)$ \\
Diabetes & $11(7.3)$ \\
Congenital illness & $7(4.7)$ \\
Multimorbidity & $5(3.3)$ \\
Cancer & $5(3.3)$ \\
Cardiovascular disease & $4(2.7)$ \\
Other serious chronic illnesses & $9(6.0)$ \\
Not known & $1(0.7)$ \\
\hline
\end{tabular}

Of the students allocated to the sham intervention, one $(0.6 \%)$ did not see their GP teacher for a debriefing discussion.

\section{Overall change in students' PPOS-D12 scores}

The mean PPOS-D12 score for both intervention groups combined was 4.19 (SD 0.47) at the start of the study, and 4.47 (SD 0.47) after the interventions, an increase of 0.27 (SD 0.44, $P<0.001$ ), indicating a significant increase in patient-centred attitudes during the study.

\section{Comparison between the active and sham intervention groups}

The PPOS-D12 scores rose by 0.23 for the active intervention group and by 0.32 for the sham intervention group $(P<0.001$ for both groups). After adjusting the different baseline scores with ANCOVA, we found no significant difference in PPOS-D12 score changes between the two groups $(P=0.426)$ (Table 3).

\section{Effect of baseline characteristics on PPOS-D12 scores at the start of the study}

Our regression analysis revealed two characteristics that significantly predicted variance in the PPOS-D12 scores at start of study (Table 4). Being a woman $(P=0.001)$ and contact with patients before medical school $(P=$ 0.032 ) were both associated with higher, more patientcentred, scores. Neither experience of a serious chronic illness in the students themselves, a friend or a close relative, nor history of previous undergraduate experience, were significant predictors of students' PPOS-D12 scores at the start of the study $(P=0.646$ and $P=0.158$ respectively).

\section{GP teachers' PPOS-D12 scores}

GP teachers' PPOS-D12 scores (4.58) were significantly higher (more patient-centred) than their students both before the interventions, $P<0.001$, and afterwards, $P=$ 0.002 (Table 5). There was no correlation between the change in students' PPOS-D12 scores and the scores of their GP teachers $(r=0.088, P=0.138)$. 
Table 3 Change in students' PPOS-D12 scores during the study

\begin{tabular}{|c|c|c|c|c|}
\hline & $\begin{array}{l}\text { All participants completing } \\
\text { both surveys }(n=306)\end{array}$ & $\begin{array}{l}\text { Allocated to active } \\
\text { intervention }(n=150)\end{array}$ & $\begin{array}{l}\text { Allocated to sham } \\
\text { intervention }(n=156)\end{array}$ & $\begin{array}{l}\text { Significance } \\
\text { level }^{*}\end{array}$ \\
\hline Increase in mean PPOS-D12 score (SD) & $0.27(0.44)$ & $0.23(0.41)$ & $0.32(0.47)$ & $p=0.426$ \\
\hline
\end{tabular}

* For difference between active and sham intervention groups, after adjustment for different baseline PPOS-D12 scores using ANCOVA

\section{Discussion}

\section{Principal findings}

While first-year medical students became more patientcentred over the course of their longitudinal clerkship in primary care, the addition of a home-based interview with a chronically ill patient did not increase the effect.

\section{Interpretation of the results}

An increase in first-year medical students' patientcentred attitudes has not been described before, and this rise may be due to the longitudinal primary care clerkship that is embedded in University of Bern's programme. Despite the careful development and successful implementation of the active intervention, the active intervention had no independent effect on students' patient-centred attitudes.

Our finding that GP teachers had higher PPOS-D12 scores than their students may indicate a trend towards patient-centredness over the long-term, perhaps as a result of increasing experience, or it may be that doctors with patient-centred attitudes are more attracted to working in general practice. However, we found no association between individual GP teachers' levels of patientcentredness and the degree of change in attitude of their allocated students.

Table 4 Linear regression analysis of effect of student baseline characteristics on PPOS-D12 scores at start of study

\begin{tabular}{|c|c|c|c|}
\hline $\begin{array}{l}\text { Baseline } \\
\text { characteristic }\end{array}$ & PPOS-D12 score (SD) & $\beta$-coefficient $(95 \% \mathrm{Cl})$ & $P$ value \\
\hline \multicolumn{4}{|l|}{ Gender } \\
\hline Female & $4.25(0.43)$ & 0.203 (0.086 to 0.315$)$ & $0.001^{*}$ \\
\hline Male & $4.08(0.51)$ & & \\
\hline
\end{tabular}

Experience of a chronic illness in the students themselves or a close relative

$$
\begin{array}{llll}
\text { Yes } & 4.22(0.48) & 0.027(-0.079 \text { to } 0.127) & 0.646
\end{array}
$$$$
\text { No } \quad 4.18(0.47)
$$

Had studied another subject as an undergraduate before starting to study medicine

\begin{tabular}{lccc} 
Yes & $4.37(0.54)$ & $0.108(-0.061$ to 0.373$)$ & 0.158 \\
No & $4.17(0.46)$ & & \\
Contact & with patients before going to medical school & \\
Yes & $4.30(0.48)$ & $0.126(0.011$ to 0.238$)$ & $0.032^{*}$ \\
No & $4.13(0.56)$ & & \\
\hline
\end{tabular}

\footnotetext{
" Significant at $p<0.05$
}

\section{Comparison with existing literature}

We did not expect an increase in students' patientcentred attitudes, because other studies had found a decrease in patient-centred attitudes in students during their medical training. For example, in the USA, medical students' PPOS scores decreased, falling from 4.61 in Year 1 to 4.46 in Year 4 [7]; Greek students' PPOS scores reduced from 3.96 in Year 4 to 3.81 in Year 6 [8]; and South African students' PPOS scores reduced from 2.65 in Year 1 to 2.25 in Year 6, with the most pronounced decrease in the first 2 years of study [9].

The University of Bern has a well-established, mandatory primary care clerkship that students begin in their first year, giving them immediate contact with patients, and this clerkship may increase the likelihood that students will develop more patient-centred attitudes. It is known that early patient exposure can have a positive effect on patientcentred attitudes [12], and longitudinal-integrated clerkships increase these attitudes regardless of specialty [31].

\section{Strengths and weaknesses of the study}

The active intervention was developed iteratively, with two pilot studies and rounds of improvement to the patient interview guide. We had a very high response rate (96.8\%) to our surveys with little loss to follow-up among students due to a rigorous recall scheme with several e-mail and phone reminders. All students who completed the study received their assigned intervention. Most in the intervention group (92.0\%) complied with the instruction to conduct the interview at the patient's residence. While only half of their students interviewed patients who had one of the four chronic conditions specified by the study team, all but one of the other students saw patients with other significant chronic conditions. Also, since patients and doctors may not always agree on which chronic condition is the primary diagnosis [32], it is possible that some of these patients did have one of the four specified conditions but did not see it as their primary problem or describe it that way to the students.

Table 5 Comparison of PPOS-D12 scores of students and their GP teachers

\begin{tabular}{ll}
\hline & Mean PPOS-D12 score (SD) \\
\hline Students at start of study & $4.19(0.47)$ \\
Students at end of study & $4.47(0.47)$ \\
GP Teachers & $4.58(0.56)$ \\
\hline
\end{tabular}


The significant imbalance between baseline PPOS-D12 scores in the two intervention groups was likely to be due to chance, as randomisation was performed independently and we detected no irregularities. We did not collect data on whether the students used the questions and topics given in the interview and debriefing guides. It may be that the single interview was too small an intervention to have a measurable effect, and that increasing the number of these would have produced a different outcome. While it is possible that the increase in PPOS-D12 scores was due to students' desire to have a socially desirable score, this seems unlikely as they had no other clinical experience or teaching in in their first year other than that described in the paper, and were unlikely to have formed an opinion on the social desirability of certain responses.

\section{Implications for research and practice}

We now know that medical students do not necessarily become less patient-centred over time, but we need to determine whether the increase in patient-centred attitudes in this study was produced by patient encounters during the primary care clerkships or by some other factor.

\section{Conclusions}

Patient-centred attitudes increased during medical students' first year of medical studies, possibly because of their longitudinal primary care clerkship. Being a woman, and contact with patients prior to medical school, were associated with higher levels of patientcentred attitudes in students at baseline. However, as a single, structured, home-based interview with a chronically ill patient had no additional effect, we do not recommend this intervention as a way to influence patientcentred attitudes. GP teachers tend to be more patientcentred than their allocated medical students,

\section{Supplementary information}

Supplementary information accompanies this paper at https://doi.org/10. 1186/s12909-020-02136-y.

\section{Additional file 1.}

\section{Abbreviations}

ANCOVA: Analysis of covariance; DALY: Disability-adjusted life years; GP: General Practitioner; PPOS: Patient-Practitioner Orientation Scale; SD: Standard Deviation

\section{Acknowledgements}

The authors would like to thank the students who piloted the project, and the students and GP teachers who completed the survey. They are also grateful to Prof. Gordon Taylor, University of Exeter, UK, for his advice on the data analysis, and to Dr. Kali Tal, University of Bern, Switzerland, for her expert advice on the manuscript.

\section{Authors' contributions}

$\mathrm{MH}, \mathrm{A}-\mathrm{LC}, \mathrm{RF}, \mathrm{SS}$ and $\mathrm{RH}$ participated in the study design. MH, A-LC, RF and $\mathrm{RH}$ were involved in the data collection. SS advised on the analysis. $\mathrm{MH}, \mathrm{A}-$ LC, RF, SS and RH each contributed to the writing and to the review of the manuscript and approved the final version. MH had overall responsibility for the study. All authors have read and approved the manuscript.

\section{Authors' information}

Michael Harris is a General Practitioner in the UK. He is Research Associate at the Institute of Primary Health Care (BIHAM), University of Bern, Bern,

Switzerland, and Honorary Senior Research Fellow, College of Medicine \& Health, University of Exeter, United Kingdom.

Anna-Lea Camenzind is a medical student and a Doctoral candidate at the Institute of Primary Health Care (BIHAM), University of Bern, Bern, Switzerland. Rita Fankhauser is a General Practitioner in Switzerland and Research

Associate at the Institute of Primary Health Care (BIHAM), University of Bern, Bern, Switzerland.

Sven Streit is a General Practitioner in Switzerland and an Assistant Professor for Primary Care at the Institute of Primary Health Care (BIHAM), University of Bern, Bern, Switzerland.

Roman Hari is a General Practitioner in Switzerland and the Head of Education at the Institute of Primary Health Care (BIHAM), University of Bern, Bern, Switzerland

\section{Funding}

This study received no specific grant from any funding agency in the public, commercial or not-for-profit sectors.

\section{Availability of data and materials}

The datasets generated during and/or analysed during the current study are available from the corresponding author on reasonable request.

\section{Ethics approval and consent to participate}

The Bern Research Ethics Commission declared that, under the Swiss law on human research (Humanforschungsgesetz, HFG), ethics committee approval was not needed for this research (BASEC-Nr: Req-2018-00059, 22nd January 2018)

This research project was part of a wider evaluation of different pedagogical methods. In an on-line survey, participants were asked whether they gave consent for their data to be used in the research project, and only the data from those that ticked the box to indicate their agreement was used in the analysis.

The study protocol was published as a password-protected pdf on October 31st 2018, available from http://www.tinyurl.com/patient-centredness

\section{Consent for publication}

The study contains no information that identifies individuals so consent for publication is not applicable.

\section{Competing interests}

The authors declare that they have no competing interests.

\section{Author details}

${ }^{1}$ Institute of Primary Health Care (BIHAM), University of Bern, Bern, Switzerland. ${ }^{2}$ College of Medicine \& Health, University of Exeter, Exeter, UK. ${ }^{3}$ Gore Cottage, Emborough, Radstock BA3 4SJ, UK.

Received: 10 April 2020 Accepted: 2 July 2020

Published online: 11 July 2020

References

1. Lewin SA, Skea ZC, Entwistle V, Zwarenstein M, Dick J. Interventions for providers to promote a patient-centred approach in clinical consultations. Cochrane Database Syst Rev. 2001;4:CD003267.

2. McWhinney IR. The need for a transformed clinical method. In: Stuart M, Roter D, editors. Communicating with medical patients. London: Sage; 1989.

3. Bauman $A E$, Fardy HJ, Harris PG. Getting it right: why bother with patientcentred care? Med J Aust. 2003 Sep 1;179(5):253-6.

4. Coulter A, Ellins J. Health Foundation (Great Britain). Patient-focused interventions: a review of the evidence. London: Health Foundation; 2006. 
5. Institute of Medicine Committee on Quality of Health Care in America. Crossing the Quality Chasm: A New Health System for the 21st Century. Washington (DC): National Academies Press (US); 2001.

6. Monrouxe $\mathrm{V}$, Rees $\mathrm{C}$. Healthcare professionalism: improving practice through reflections on workplace dilemmas. New Jersey: Wiley-Blackwell; 2017. 272 p.

7. Haidet P, Dains JE, Paterniti DA, Hechtel L, Chang T, Tseng E, et al. Medical student attitudes toward the doctor-patient relationship. Med Educ. 2002 Jun;36(6):568-74.

8. Tsimtsiou Z, Kerasidou O, Efstathiou N, Papaharitou S, Hatzimouratidis K, Hatzichristou D. Medical students' attitudes toward patient-centred care: a longitudinal survey. Med Educ. 2007;41(2):146-53.

9. Archer E, Bezuidenhout J, Kidd MR, van Heedfen B. Making use of an existing questionnaire to measure patient-centred attitudes in undergraduate medical students: a case study. AJHPE. 2014;6(2):150-4

10. Ishikawa H, Son D, Eto M, Kitamura K, Kiuchi T. Changes in patient-centered attitude and confidence in communicating with patients: a longitudinal study of resident physicians. BMC Med Educ. 2018;18:20.

11. Beattie A, Durham J, Harvey J, Steele J, McHanwell S. Does empathy change in first-year dental students? Eur J Dent Educ. 2012 Feb;16(1):e111-6.

12. Goldie J, Dowie A, Cotton P, Morrison J. Teaching professionalism in the early years of a medical curriculum: a qualitative study. Med Educ. 2007 Jun; 41(6):610-7.

13. Frenk J, Chen L, Bhutta ZA, Cohen J, Crisp N, Evans T, et al. Health professionals for a new century: transforming education to strengthen health systems in an interdependent world. Lancet Lond Engl. 2010 Dec 4; 376(9756):1923-58.

14. Yuen JK, Breckman R, Adelman RD, Capello CF, LoFaso V, Reid MC Reflections of medical students on visiting chronically ill older patients in the home. J Am Geriatr Soc. 2006 Nov;54(11):1778-83.

15. Anderson EE, Boyd B, Qureshi NK, Stirling JM, McCarthy V, Kuczewski MG. Operation Homefront: meeting clerkship competencies with home visits to families of children with special needs. Acad Pediatr. 2019;19(2):170-6.

16. Denton GD, Rodriguez R, Hemmer PA, Harder J, Short P, Hanson JL. A prospective controlled trial of the influence of a geriatrics home visit program on medical student knowledge, skills, and attitudes towards care of the elderly. J Gen Intern Med. 2009 May;24(5):599-605.

17. Flaherty J, Fabacher D, Miller R, Fox A, Boal J. The Determinants of Attitudinal Change Among Medical Students Participating in Home Care Training: A Multi-Center Study - PubMed. Acad Med. 77(4):336-43.

18. Institute for Health Metrics and Evaluation. Global burden of diseases, injuries, and risk factors study 2010, Switzerland. 2012.

19. Krupat E, Rosenkranz SL, Yeager CM, Barnard K, Putnam SM, Inui TS. The practice orientations of physicians and patients: the effect of doctor-patient congruence on satisfaction. Patient Educ Couns. 2000 Jan;39(1):49-59.

20. Kiessling C, Fabry G, Rudolf Fischer M, Steiner C, Langewitz WA. German translation and construct validation of the patient-provider-orientation scale (PPOS-D12). Psychother Psychosom Med Psychol. 2014 Mar;64(3-4):122-7.

21. Karnieli-Miller O, Vu TR, Holtman MC, Clyman SG, Inui TS. Medical Students' Professionalism Narratives: A Window on the Informal and Hidden Curriculum. Acad Med. 2010;85:124-33.

22. Inui T. A flag in the wind: educating for professionalism in medicine. [Internet]. Washington, USA: Association of American Medical Colleges; 2003 [cited 2020 Jun 1]. Available from: http://users.clas.ufl.edu/msscha/Readings/ flaginthewind_professionalism_med.pdf.

23. Reddy S, Farnan J, Yoon J, Leo T, Upadhyay G, Hj H, et al. Third-year medical students' participation in and perceptions of unprofessional behaviors. Acad Med. 2007 Oct 1;82(10 Suppl):S35-9.

24. Jarmuz P. More than a diagnosis: enabling medical students to understand and address the patient's psychological needs [Internet]. [Syracuse, USA] Syracuse University; 2014 [cited 2020 May 28]. Available from: https:// surface.syr.edu/honors_capstone/775.

25. Clarke A, Hanson EJ, Ross H. Seeing the person behind the patient: enhancing the care of older people using a biographical approach. J Clin Nurs. 2003 Sep;12(5):697-706.

26. Mead N, Bower P. Patient-centredness: a conceptual framework and review of the empirical literature. Soc Sci Med. 2000 Oct;51(7):1087-110.

27. Burns C. Using debriefing and feedback in simulation to improve participant performance: an educator's perspective. Int J Med Educ. 2015;6:118-20.

28. Horsfall J. Clinical placement: prebriefing and debriefing as teaching strategies. Aust J Adv Nurs. 1990 Nov:8(1):3-7.
29. Barwani A. Effective debriefing helps achieve learning objectives in the classroom. J Educ Educ Dev. 2015;1(2):156-65.

30. Kolb D. Experiential learning: experience as a source of learning and development, vol. 1. Englewood Cliffs: Prentice Hall; 1984.

31. Gaufberg E, Hirsh D, Krupat E, Ogur B, Pelletier S, Reiff D, et al. Into the future: patient-centredness endures in longitudinal integrated clerkship graduates. Med Educ. 2014 Jun;48(6):572-82.

32. Herzig L, Mueller Y, Haller DM, Zeller A, Neuner-Jehle S, Déruaz-Luyet A, et al. Family practitioners' top medical priorities when managing patients with multimorbidity: a cross-sectional study. BJGP Open. 2019;3(1): bjgpopen18X101622.

\section{Publisher's Note}

Springer Nature remains neutral with regard to jurisdictional claims in published maps and institutional affiliations.

\section{Ready to submit your research? Choose BMC and benefit from:}

- fast, convenient online submission

- thorough peer review by experienced researchers in your field

- rapid publication on acceptance

- support for research data, including large and complex data types

- gold Open Access which fosters wider collaboration and increased citations

- maximum visibility for your research: over $100 \mathrm{M}$ website views per year

At BMC, research is always in progress.

Learn more biomedcentral.com/submissions 